\title{
Deterioration of Strength of Lime-Stabilized Soils Subjected to the Repetition of Crush and Compaction
}

\author{
Y. Nabeshima, S. Tomohisa, and Y. Miura
}

\begin{abstract}
A huge amount of surplus soil and muddy soil was produced from the construction earth works in Japan. To reuse these soils in the construction sites, the soil improvements by mixing with cement or lime were sometime adopted. Recently, the case in which the improved soil was excavated, refilled and compacted was supposed. As the improved soil was excavated, refilled and compacted, it was necessary to evaluate the strength of the improved soil. However, the strength of stabilized soil was decreased by repetition of excavation, refill and compaction processes. In this paper, the deterioration of strength of the lime-stabilized soil subjected to the repetition of crush and compaction process was discussed. A series of unconfined compression tests were carried out to evaluate the deterioration of strength of the stabilized soil by repeating crush and compaction processes. As a result, it is found that the strength was decreased by repetition of crush and compaction processes from that without the crush and compaction process. However, the deteriorated strength of the stabilized soil which was repeatedly crushed and compacted had similar strength to that of the soil with one-time of crush and comaction process.
\end{abstract}

Index Terms-Deterioration, strength, repetition, crush, compaction.

\section{INTRODUCTION}

A huge amount of surplus soil and muddy soil was produced from many construction earth works in Japan [1], they were usually soft, weak and high water content. It is necessary to improve their mechanical properties for the reuse as construction materials in earth works. The soil improvements by mixing with stabilizers such as cement or lime were popular techniques. However, the cement improvement has some difficulties such as the leachate of hexavalent chromium and strong alkali [2], [3]. It was also difficult to stabilize the soil containing high organic matters such as organic soils. Alternatively, the soil stabilization by lime was sometimes adopted to improve soil properties. The lime-stabilized soil shows comparatively low alkali than that of the cement-stabilized soil. The soil improvement by mixing with lime had many field applications in Japan, for example proposed by Namri, Onituska and Tanaka [4].

Recently, the case in which the improved soil was excavated to renew or update the facilities was supposed, and the excavated soil was refilled and compacted after finishing the renewal work [5]. As the soil was excavated, refilled and

Manuscript received May 9, 2014; revised July 15, 2014.

The authors are with the Akashi National College of Technology, Akashi, Hyogo $6748501 \quad J a p a n$ (e-mail: nabesima@akashi.ac.jp, tomohisa@akashi.ac.jp). compacted many times, it is necessary to evaluate the strength of the soil. However, the strength of stabilized soil was decreased by repetition of excavation, refill and compaction processes.

In this paper, the deterioration of strength of the lime-stabilized soil subjected to the repetition of crush and compaction process was discussed. A series of unconfined compression tests were carried out to evaluate the deterioration of strength of the stabilized soil before and after crush and compaction process. The deterioration characteristics of the improved soil which was repeated the processes was examined trough the model tests.

\section{MATERIALS IN THIS TEST}

\section{A. Test Soil}

The test soil was taken near the college in Ono city, Hyogo prefecture. The soil properties are shown in Table I. It was classified to the sandy fine soil which contains sand, silt and clay. The percentage of silt and clay was comparatively high about 63 and with high water contents. Table II shows the elemental conditions of the test soil. The ignition loss is $6.4 \%$ which means the test soil contains comparatively high organic matters and is hard to improve by cement. The test soil also contains $\mathrm{Fe}_{2} \mathrm{O}_{3}$ about $4.4 \%$ and shows reddish color.

TABLE I: SOIL PROPERTIES

\begin{tabular}{|c|c|c|c|}
\hline \multicolumn{3}{|c|}{ Natural water content $(\%)$} & 19.1 \\
\hline \multicolumn{3}{|c|}{ Liquid limit (\%) } & 44.3 \\
\hline \multicolumn{3}{|c|}{ Plastic limit (\%) } & 21.3 \\
\hline \multicolumn{3}{|c|}{ Plasticity index } & 23.0 \\
\hline \multicolumn{3}{|c|}{ Density of soil particle $\left(\mathrm{g} / \mathrm{cm}^{3}\right)$} & 2.66 \\
\hline \multirow{4}{*}{ Gradation } & \multicolumn{2}{|l|}{ Gravel (\%) } & 3.9 \\
\hline & \multicolumn{2}{|l|}{ Sand $(\%)$} & 33.1 \\
\hline & \multicolumn{2}{|l|}{ Silt $(\%)$} & 21.9 \\
\hline & \multicolumn{2}{|l|}{ Clay $(\%)$} & 41.1 \\
\hline \multicolumn{3}{|c|}{ Classification of soil } & ine soil [FS] \\
\hline \multicolumn{4}{|c|}{ TABLE II: ELEMENT CONDITIONS } \\
\hline Elements & Percentage $(\%)$ & Elements & Percentage $(\%)$ \\
\hline $\mathrm{SiO}_{2}$ & 73 & $\mathrm{MgO}$ & 0.3 \\
\hline $\mathrm{Al}_{2} \mathrm{O}_{3}$ & 13 & $\mathrm{Na}_{2} \mathrm{O}_{3}$ & 0.16 \\
\hline $\mathrm{Fe}_{2} \mathrm{O}_{3}$ & 4.4 & $\mathrm{~K}_{2} \mathrm{O}$ & 0.95 \\
\hline $\mathrm{CaO}$ & 0.57 & $\mathrm{TiO}_{2}$ & 0.45 \\
\hline \multicolumn{2}{|c|}{ Ignition Loss (\%) } & \multicolumn{2}{|c|}{6.4} \\
\hline
\end{tabular}

\section{B. Stabilizer}

The test soil was soft and high water content, so the stabilizer was necessary to improve the strength of the soil. 
As shown in Table I, the soil improvement by mixing with cement was hard because the ignition loss was high and contains organic matters. Organic matters disturb the hardening of cement. Considering high alkali leachate, the lime was selected as the stabilizer. The stabilizer contains $\mathrm{CaO}, \mathrm{CaSO}_{4}, \mathrm{SiO}_{2}$ and $\mathrm{Al}_{2} \mathrm{O}_{3}$, which was analyzed by Midorishoji Co., Ltd [6]. Because the dominant component of the stabilizer was $\mathrm{CaO}$, the hardening mechanism seems to be similar to that of the burnt lime. The value of $\mathrm{pH}$ was comparatively lower than that of cement, the $\mathrm{pH}$ value decreases to the neutral zone until about 2 weeks, which shows the environment-conscious stabilizer. The initial $\mathrm{pH}$ value of original soil shows 9.0, and the value after mixing lime at additive late of $1 \%$ shows 11.5 and it decreased until 9.2 , nearly initial value, after 90 days.

\section{Methodology}

In this study, the strength of original test soil was first examined by a series of unconfined compression test under the various water content conditions. Then, the strength of the soil improved by lime was examined as an initial strength of the lime-improved soil under the various curing period through the unconfined compression test. After confirming the strength characteristics of the original soil and the lime-improved soil, the degradation of the strength of the soil improved by lime subjected to the repetition of crush and compaction was examined. The process of excavation, refill and compaction in the field was modeled by the operation of crush and compact of specimen of the lime-improved soil.

\section{A. Strength of Original Soil}

The strength of the original test soil was examined by a series of unconfined compression test under the various water content conditions. Water content of the test soil was adjusted to the predetermined value to investigate the original soil strength relationship with water content. Cylindrical specimens which have $50 \mathrm{~mm}$ in diameter and $100 \mathrm{~mm}$ in height were made by a tamping with 5 layers and 50 blows per each layer in a cast-iron mold without any air voids. A series of unconfined compression test was carried out with the constant rate at $1.0 \% / \mathrm{min}$.

\section{B. Strength of Lime-Improved Soil}

The strength of the soil improved by lime was examined by the unconfined compression test under the various curing period. Initial water content of test soil was arranged at 19.1 $\%$ and additive rate of $2 \%$ of burnt lime was mixed by the mass percentage. After 3 hours from mixing, cylindrical specimens were made by the same method with the original soil, because burnt lime $(\mathrm{CaO})$ expanded by the water absorption. Test specimens were cured under the conditions of temperature 20 degree Celsius and humidity $60 \%$. After the predetermined curing periods, a series of unconfined compression test was carried out. The curing periods were changed from $0,7,14,21,28,60$ to 90 days.

\section{Strength Subjected to Repetition of Crush and Compaction}

To evaluate the degradation of the strength of the soil improved by lime subjected to the repetition of excavation, refill and compaction process, a series of unconfined compression test was carried out for the specimens which was made by the crushed and compacted by using the lime-stabilized soil. The process of excavation, refill and compaction process in the actual earth work was modeled by the operation of crush and compaction. The test procedures were shown in Fig. 1.

1) Initial water content of the improved soil was arranged at $19.1 \%$ and additive rate of 1,2 and $3 \%$ of burnt lime was mixed by the mass percentage.

2) After 3 hours from mixing, three cylindrical specimens were made by tamping method.

3) Unconfined compression test was carried out for three specimens.

4) After 3 days from finishing unconfined compression test, all specimens were crushed into grains under $5 \mathrm{~mm}$.

5) The water content of the grains was adjusted at the initial water content and the grains were compacted

6) Unconfined compression test was carried out for three specimens which were made of the reproduced soil.

7) The operation from 4) to 6) was repeated five times.

The deterioration of strength of the lime-improved soil subjected to repetition of crush and compaction process was evaluated through this procedures.

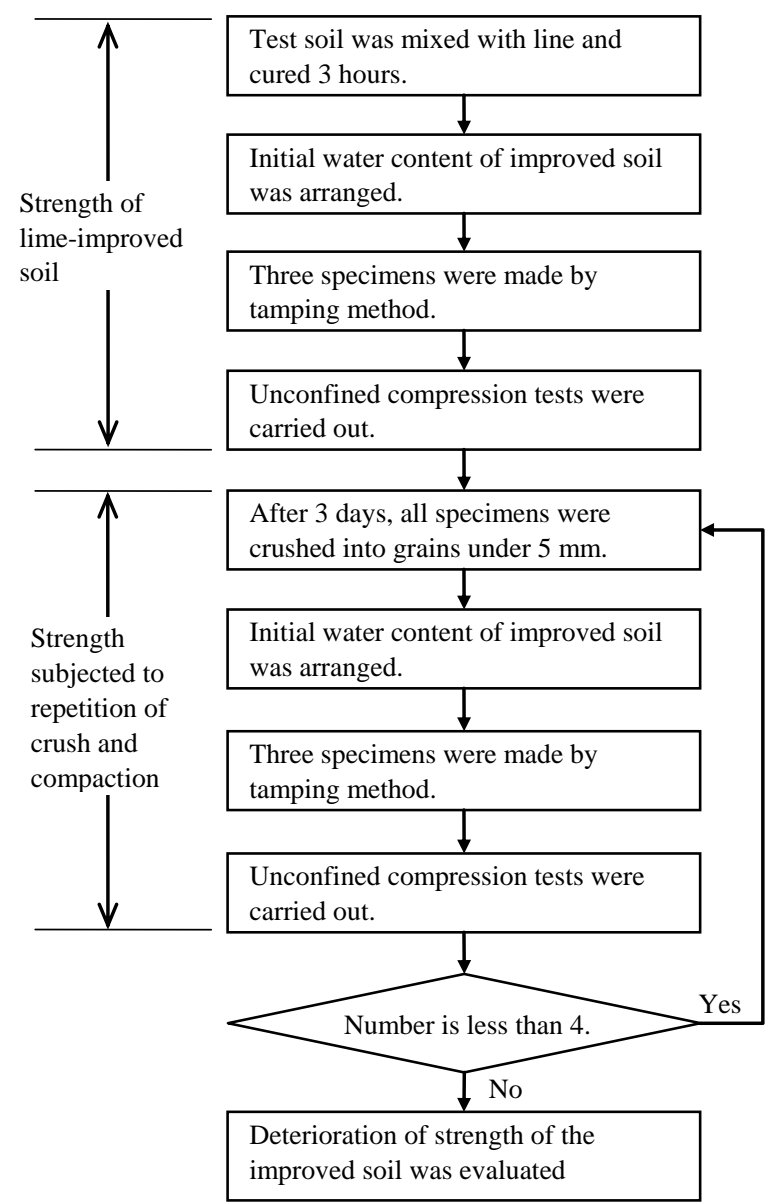

Fig. 1. Test procedures and flow of this study.

As shown in Fig. 1, the initial strength of the lime-improved soil was examined in the first routine and the deterioration of strength was evaluated at every time through the repetition of the crush and compaction process in the second routine. 


\section{Strength of Long-Term Cured Soil}

The renewal or update works might be not carried out in short time, they sometimes carried out after long time passed. In this case, the excavation, refill and compaction processes were made after the hardening reaction of lime had completely finished. This means the restoration of strength by the hardening effect of line is unexpected. To evaluate the deterioration of the strength of the lime-improved soil subjected to repetition of crush and compaction process, a series of unconfined compression test was carried out by using long-term cured soil improved by lime. The test soil had been cured for 1 year after mixing with lime, because the strength of the lime-stabilized soil showed almost constant after 90 days passed. The test procedures of preparation of specimens and unconfined compression test were the same as described above.

\section{Test Results AND Discussions}

\section{A. Strength of Original Test Soil}

Fig. 2 shows the variation of unconfined compressive strength and initial water content of original soil, in which a unique relationship between them was observed. The unconfined compressive strength showed around $600 \mathrm{kPa}$ at about $13 \%$ of water content. As the water content increased, the unconfined compressive strength rapidly decreased. When the water content exceeded $20 \%$, the compressive strength decreased under $100 \mathrm{kPa}$. From Fig. 2, it was confirmed that he unconfined compressive strength of original soil at natural water content of $19.1 \%$ was under 100 $\mathrm{kPa}$.

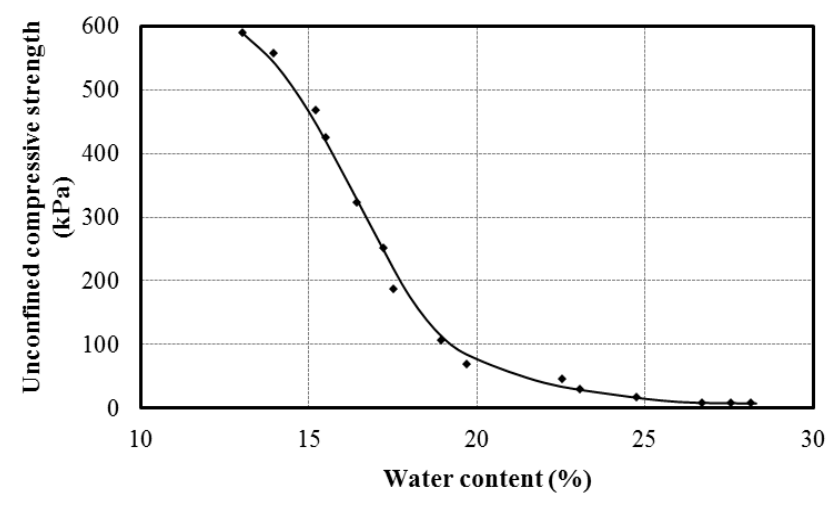

Fig. 2. Unconfined compressive strength and water content of the original soil.

\section{B. Strength of Lime-Improved Soil}

Fig. 3 shows the variation of unconfined compressive strength and cured period of the lime-improved soil when the additive rate of stabilizer was $2 \%$. Filled circles in Fig. 3 show test data of unconfined compression tests and a solid line shows average value of test data. As shown in Fig. 2, the unconfined compressive strength at $19.1 \%$ of water content showed about $100 \mathrm{kPa}$. After mixing with lime, the unconfined compressive strength increased about $250 \mathrm{kPa}$ without curing period. It was because of the hardening effect of stabilizer. The strength of the soil improved by stabilizers generally increases as the curing period increases because of the hardening effect is mobilized, Fig. 3 also shows that the unconfined compressive strength of the soil improved by lime increased as the curing period increased. However, the rate of increase in strength gradually decreased as the curing period increased. The rate of increase before 30 days was clearly larger than that after 60 days. Thus, the hardening effect of the lime which was used in this study tended to go down after 90 days. It was reported by Kitazume and Takahashi [7] that the long-term strength of lime-treated soil has increased three-times from 64 days to 11 years and kept an almost constant strength until after 27 years. Also, it was reported that the clear deterioration of strength was not recognized.

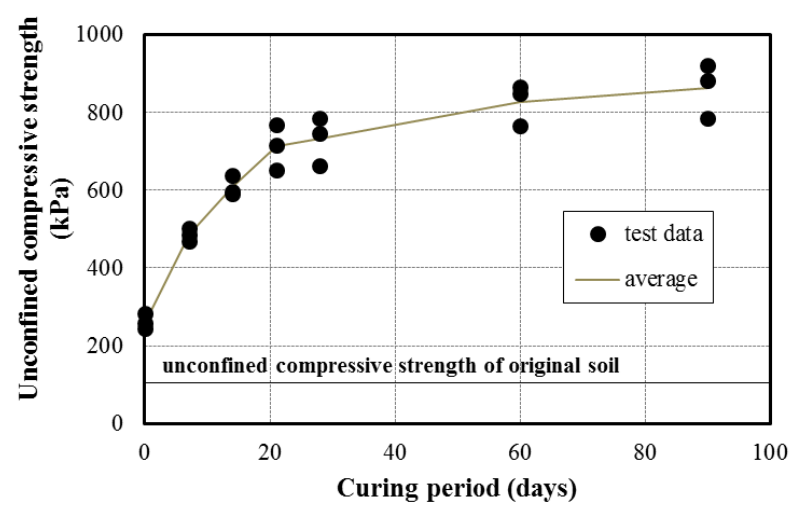

Fig. 3. Unconfined compressive strength and cured period of the lime-improved soil.

\section{Strength Subjected to Repetition of Crush and Compaction}

Fig. 4 to Fig. 6 show the variation of unconfined compressive strength and water content of the lime-improved soil when the additive rate of stabilizer was 1,2 and $3 \%$. In these figures, the number of the repetition crush and compaction process was also shown. To compare the strength before and after repetition of crush and compaction process, the unique relationship of unconfined compressive strength and initial water content of original soil was also shown. The unconfined compressive strength of the lime-stabilized soil generally tended to decrease as the water content increased regardless of the additive rate of stabilizer. The strength of the lime-stabilized soil in Fig. 4 to Fig. 6 seems to be scattering a little. It was reported by Fukushima et al. [8] that the strength of the crushed and compacted soil was bigger as the grain size was bigger. Therefore, the scattering of the strength of lime-stabilized soil subjected to the repetition of crush and compaction process depended on the grain size.

Fig. 4 shows the relationship between unconfined compressive strength and water content of original soil without stabilizer overlapped on the test data at the additive rate of stabilizer $1 \%$ regardless of the number of crash and compaction process. This is because that the increase in strength by mixing with stabilizer was small at the additive rate of stabilizer $1 \%$, which means hardening effect was small with this additive rate of stabilizer. Therefore, the decrease in strength subjected to the prepetition of crush and compaction process was small.

In contrast, it was shown in Fig. 5 and Fig. 6 that the relationship between unconfined compressive strength and 
water content of original soil was smaller than the test data mixed with stabilizer even in the cases subjected to the repetition of crush and compaction processes. This means that the hardening effect was mobilized with the additive rate of lime at 2 and $3 \%$ and the strength of lime-stabilized soil became much bigger than that of original soil. The strength of the lime-improved soil subjected to the repetition of crush and compaction process depends on the number of the repetition process from Fig. 5 and Fig. 6. The unconfined compressive strength decreased as the number of the repetition of crush and compaction process increased. This means that the soil grains which were solidified by lime were crushed during crush and compaction process. Crushing patterns of solidified soil were complex as shown by Yoshimoto et al. [9]. However, it seemed that the solidified soil grains were not completely crushed because the strength of the improved soil subjected to crush and compaction processes was larger than that of original soil at the same water content.

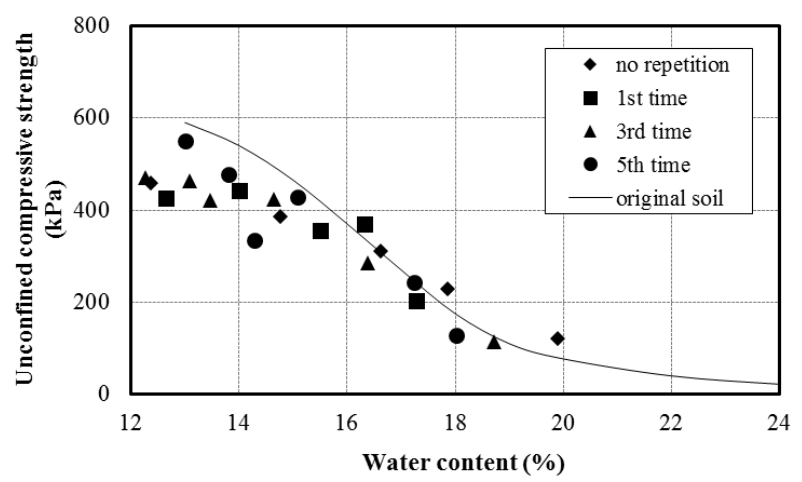

Fig. 4. Unconfined compressive strength and water content of the lime-improved soil at the additive rate of stabilizer $1 \%$.

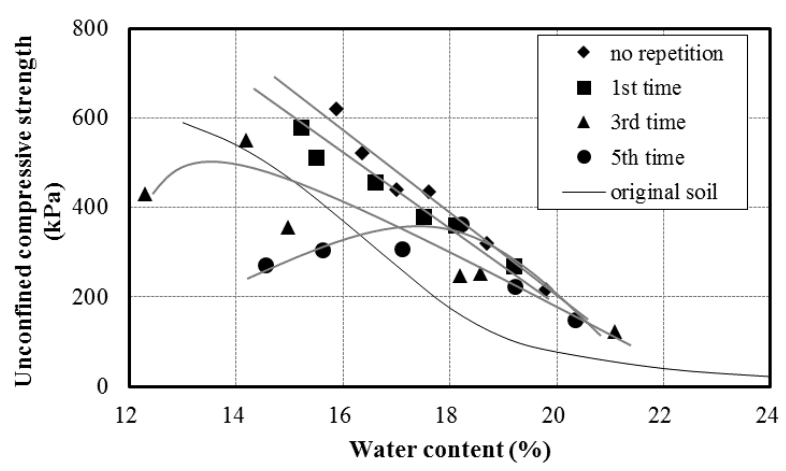

Fig. 5. Unconfined compressive strength and water content of the lime-improved soil at the additive rate of stabilizer $2 \%$.

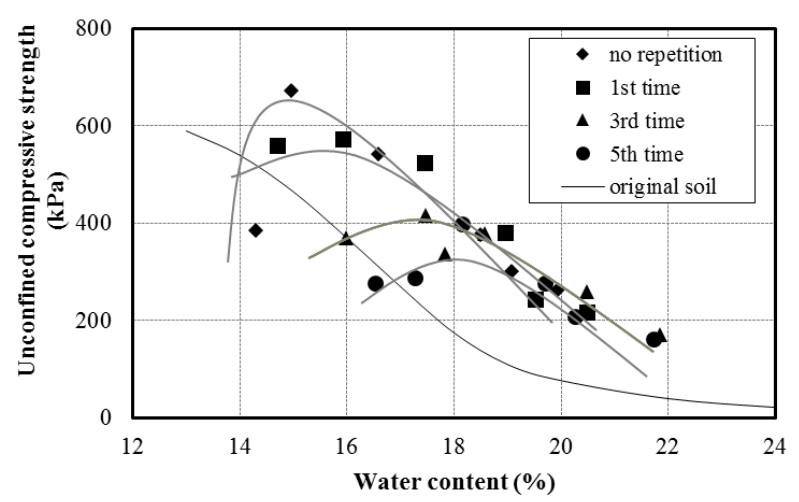

Fig. 6. Unconfined compressive strength and water content of the lime-improved soil at the additive rate of stabilizer $3 \%$.
As the water content became high, the strength of improved soil showed a unique value at the same water content regardless of the number of the crush and compaction processes. Compared Fig. 5 and Fig. 6, the unique value in Fig. 5 was smaller than that in Fig. 6, this was because the additive rate of lime was smaller.

\section{Strength of Long-Term Cured Soil}

To investigate the strength of the improved soil after long time passed from the soil improvement, the unconfined compressive strength of the lime-improved soil subjected to the crush and compaction process was examined. Fig. 7 shows the variation of unconfined compressive strength with the number of the repetition of the crush and compaction processes, the strength of the original soil was also shown in this figure. From this figure, the unconfined compressive strength at every additive rate of stabilizers showed almost constant regardless of the number of the repetition of the crush and compaction processes. This means that the strength at the first crush and compaction process has been kept. As the unconfined compression tests were carried out after one year from the soil improvement, the hardening effect had completely finished. The strength of the improved soil subjected to the crush and compaction process would not increase again. Thus, regardless of the repetition of the crush and compaction processes, the unconfined compressive strength of the improved soil which long time had passed can be evaluated by the strength at the first crush and compaction process.

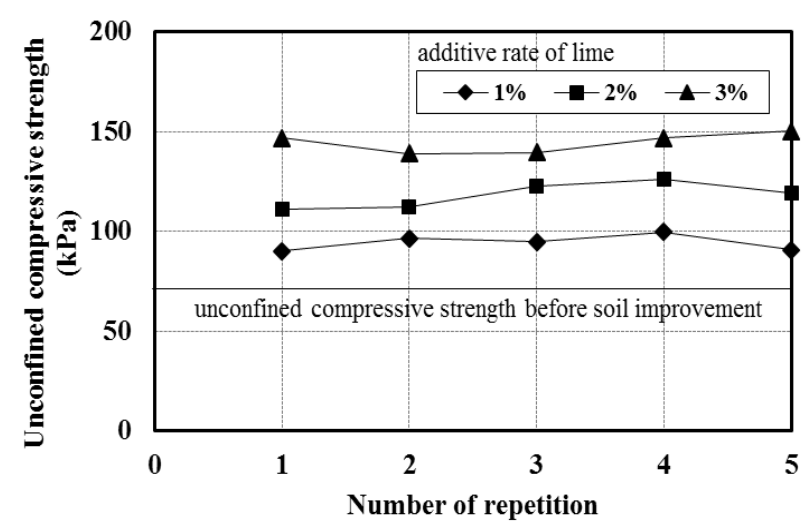

Fig. 7. Unconfined compressive strength and water content.

From Fig. 7, the strength of the improved soil subjected to the crush and compaction process became larger as the additive rate of stabilizer increased.

\section{CONCLUSIONS}

In this paper, the deterioration of strength of the lime-stabilized soil subjected to the repetition of excavation, refill and compaction processes was discussed. Main conclusions were summarized as follows:

1) The unconfined compressive strength of the soil improved by lime increased as the curing period increased, however, the hardening effect of the lime which was used in this study tended to go down after 90 days.

2) At the additive rate of stabilizer $1 \%$, the decrease in 
unconfined compressive strength of the lime-improved soil subjected to the prepetition of crush and compaction process was small. At the additive rate of stabilizer 2 and $3 \%$, the strength subjected to the repetition of crush and compaction process depends on the number of the repetition process.

3) As the water content became high, the unconfined compressive strength of lime-improved soil showed a unique value at the same water content regardless of the number of the crush and compaction processes.

4) After long time passed from the soil improvement, the unconfined compressive strength at every additive rate of stabilizers showed almost constant regardless of the number of the repetition of the crush and compaction processes.

5) Regardless of the repetition of the crush and compaction processes, the unconfined compressive strength of the lime-improved soil which long time had passed can be evaluated by the strength at the first crush and compaction process.

\section{REFERENCES}

[1] Ministry of Land, Infrastructure, Transport and Tourism, "Trend of the discharge amount of construction by-products," Substantial Investigation of Construction by-Products in 2008, March 2010.

[2] Y. Kuroda and M. Kawaguchi, "Leaching behavior of hexavalent chromium from recycled concrete materials and evaluation of environmental safety," Research Reports of Shimizu Corporation, vol. 88, pp. 97-106, Feb. 2011.

[3] Y. Kohata, "Mechanical property of liquefied stabilized soil and further issues," J. of JSCE, vol. 62, no. 4, pp. 618-627, Oct. 2006
[4] M. Namri, K. Onituska, and S. Tanaka, "An attempt on geotechnical utilization of super soft Ariake clay as a construction material," Tsuchi-to-Kiso, vol. 46, no. 8, pp. 17-20, August 1998.

[5] T. Fujikawa and K. Sato, "Mechanical properties and possibility pf the repetitive use of cement stabilized soil," J. Soc. of Material Science, vol. 63, pp. 61-66, Jan. 2014.

[6] Midorishoji Co., Ltd. Green-earth. [Online]. Available: http://www.midorisyoji.jp/040_products/products_green_earth.php

[7] M. Kitazume and H. Takahashi, "Long term property of lime treated marine clay,” J. of JSCE, vol. 64, no. 1, pp. 144-156, March 2008

[8] S. Fukushima, A. Kitajima, K. Ishiguro, Y. Ikeda, K. Sakamaki, and S. Tani, "Applicability of cement-stabilized pond-mud soil as embankment material for irrigation pond dam repairmen," J. of JSCE, vol. 666, no. III-53, pp. 99-116, Dec. 2000.

[9] K. Yoshimoto, M. Hyodo, Y. Nakata, S. Murata, T. Hongo, and A Oonaka, "Particle characteristics of granulated coal ashes as geomaterial," J. Soc. of Material Science, vol. 54, pp. 1111-1116, Nov. 2005 .

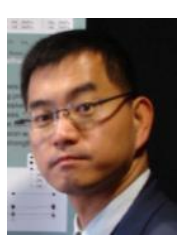

Y. Nabeshima was born in Japan in 1965. He got the B.Sc. degree in 1988, M.Sc degree in 1990 and Ph.D. degree in civil engineering from Osaka University, Japan in 1997.

Now, he is a professor at Akashi National College of Technology and the departmental dean of civil engineering.

Prof. Nabeshima's research area is in reuse and recycling of surplus soil and muddy soil as a geotechnical material. To reuse soft soil, many kinds of soil improvement techniques are evaluated. He has many scientific publications about soil mechanics and geo-environmental engineering.

S. Tomohisa was born in Japan in 1950. He graduated the Akashi Nationa College of Technology in 1970 and he was retired the college in 2013 . He is a professor emeritus with the Akashi National College of Technology now.

Y. Miura was born in Japan in 1993 and a former student of advanced course with the Akashi National College of Technology. He graduated from the advanced course of the college in 2014 and he is working as an engineer now. 